\title{
Razi and his Concepts on Bone and Joint Disorders
}

\author{
Ahmadreza Afshar, MD ${ }^{1 *}$; Ali Tabrizi, MD $^{1}$ \\ 'Department of Orthopedics, Imam Khomeini Hospital, Urmia University of Medical Sciences, Urmia, Iran
}

\begin{abstract}
This brief review presents Razi's concepts of bone and joint disorders. Razi differentiated between ligaments, tendons, and nerves and recognized the role of the brain, spinal cord, and peripheral nervous system in the perception of senses and voluntary movements. He described paralysis and loss of sensation following brain, spinal cord, and peripheral nervous system injuries. Razi presented an early concept of compartment syndrome. Razi's approach to fracture management is very similar to the current concept of functional bracing for some fractures. Razi mentioned suturing the wounds and ligation of bleeding large vessels. He cautioned about phlebotomy in the antecubital fossa as it may become complicated by the adjacent arterial and nerve injuries. Razi treated osteomyelitis by removing the infected and necrotic bone by sawing, cutting, and rasping. He also documented arthralgia, painful hip, and sciatic pain and made a sharp distinction between arthralgia and gout. He indicated the gout origin as the production of a waste substance that the body fails to expel. Razi's basic concepts on the bone and joint disorders established a foundation for modern orthopedic science.

Keywords: Arthralgia, Bone diseases, Gout, Joint disorders, Orthopedics

Cite this article as: Afshar A, Tabrizi A. Razi and his concepts on bone and joint disorders. Arch Iran Med. 2020;23(9):624-628. doi: 10.34172/aim.2020.74.
\end{abstract}

Received: April 10, 2020, Accepted: June 24, 2020, ePublished: September 1, 2020

\section{Introduction}

Abu Bakr Muhammad ibn Zakariya al-Razi (865-935) (Rhazes in Latin) was born in Rayy, near the present-time Tehran, Iran (Figure 1). Young Razi played thelute; however, his income was not enough; therefore, he pursued a career as a goldsmith. He performed experiments in the field of chemistry and alchemy and discovered alcohol, sulfuric acid, ammonium chloride, and some other chemicals. He systematically classified chemical substances, chemical reactions, and laboratory instruments. When his eyesight became blurred due to exposure to chemical reactions, he abandoned chemistry and began to learn medicine. ${ }^{1-3}$

Razi was a polymath and a prolific author. He wrote nearly 200 books, treatises, and monographs on different subjects including pharmacy, chemistry, philosophy, medicine, music, and theology. Many of Razi's works have been lost and are not available. Most of Razi's written heritage is in Arabic; however, many of his works have been translated into different languages. Razi's most influential works were on medicine. Razi is particularly best known for his scientific methodology in advancing medicine through clinical experiments and critical thinking rather than theories and speculations. Razi's concepts influenced successor scientists and physicians in Persia and around the world. Razi's most comprehensive book of medicine " $\mathrm{Al}$ Hawi fi-Tebb" (Liber Contenens in Latin; Comprehensive Book in English) was repeatedly printed during the 15th and 16th centuries in Europe. ${ }^{1-6}$ The current brief review is focused on Razi's concepts on bone and joint disorders.

\section{Razi's Concepts on Orthopedics}

"Al-Hawi fi-Tebb" (Al-Hawi) is the most important and voluminous compilation of Razi written in Arabic in the 10th century. Al-Hawi is a medical encyclopedia; its compilation took 15 years of Razi's medical career and further reduced his eyesight. Al-Hawi includes Razi's personal and clinical experience in Baghdad and Ray. This book constituted a complete course of medical science until the time of Razi, in which he wrote critiques and commented on the preceding physicians' views along with an updated description of the diseases. ${ }^{6,7}$ The book "Tebb-e Al Mansouri" (Liber Almansoris in Latin) is also a brief review of Razi's knowledge of medicine. Razi wrote

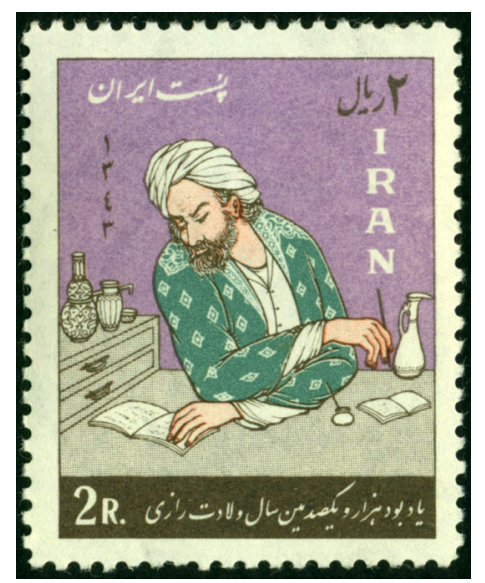

Figure 1. In 1964, Razi's 1100th birth anniversary was honored on a stamp issued by Iran.

*Corresponding Author: Ahmadreza Afshar, MD; Department of Orthopedics, Urmia University of Medical Sciences, Imam Khomeini Hospital. Modaress St., Ershad Blv., Urmia, 57157 81351, Iran. Tel: +98-91-23131556; Email: afshar_ah@yahoo.com 
the book in Arabic and arranged it in 10 chapters between the years 903 and 908 AD. Razi dedicated the book to Amir Al-Mansur Ibn Ishaq, the Samanid dynasty governor of Rayy in that time. At the beginning of "Tebb-e Al Mansouri", Razi presents information about the aims and scopes of each chapter similar to the modern concepts of lesson and course planning. ${ }^{8}$ Al-Hawi as well as "Tebb-e Al Mansouri" discussed all branches of medicine including the bone and joint disorders. ${ }^{5-7}$

Razi was familiar with human anatomy including osteology, myology, neurology, and anatomy of the arteries and veins. He recognized different types of bones including long, short, cortical cancellous and sesamoid bones as well as ligaments and tendons. Razi was a pupil of the Greek school of anatomy mainly based on Galen's works on anatomic descriptions. Although Galen had mentioned that nerves and tendons are of the same nature, Razi differentiated between ligaments, tendons, and nerves. Razi recognized the role of the brain, spinal cord, and peripheral nervous system in the perception of senses and voluntary movements. He described paralysis and loss of sensation following brain, spinal cord, and peripheral nervous system injuries. Razi also described treatments of the lacerations adjacent to peripheral nerves, peripheral nerves contusions, and nerve severance; however, Avicenna (980-1037) is credited for the first description of repairing cut peripheral nerves. ${ }^{5-8}$

Razi described the elaborate anatomy of the superficial veins due to its importance in bloodletting and phlebotomy. ${ }^{8}$ Razi believed that some diseases arise from excessive blood and waste substances circulating in the blood. Phlebotomy and bloodletting were common surgeries on the limbs to dispose of the waste substances and reduce body inflammation. He described phlebotomy on several different veins each for a different indication; however, he cautioned about phlebotomy in the antecubital fossa as it may become complicated by the adjacent arterial and nerves injuries. ${ }^{7}$

Razi had presented the concepts of fracture treatment (Figures 2 and 3). He was aware of fracture treatment in the Greek school of medicine and presented positive and negative critiques mainly regarding Galen and Hippocrates' concepts. Razi indicated that fracture of the large bones shall not be left untreated because of the apparent deformity and presence of crepitation on palpation at the fracture site. He recommended reducing the fractures and correcting the alignment of the limb with gentle traction and counter-traction without inducing further pain. Razi also warned that shoulder and hip dislocations may be missed as they are covered by large masses of muscles; however, dislocations must be reduced before the establishment of swelling and inflammation. To reduce common shoulder dislocations, Razi presented several techniques including traction, counter-traction, and Hippocratic reduction techniques. To immobilize the fractured limbs, Razi made frames consisting of cotton bandages and wood strips. He warned about tight bandages and congestion in the distal part of the limb. Moreover, he indicated that the patient's pain must not increase by immobilization. If the patient feels itching or severe pain, then the frame must be removed. In this way, Razi presented an early concept of compartment syndrome long before Richard von Volkman described the compartment syndrome and its related contracture in the 19th century. Razi also described long wooden frames, pads, and wedges to correct alignments and casts consisting of lime (calcium oxide) and egg white to immobilize the fractured limbs. ${ }^{5-7}$

As is well known, a hematoma is prone to development of infections. Razi also noted that a fracture hematoma may develop infection; therefore, he recommended removing
(A)

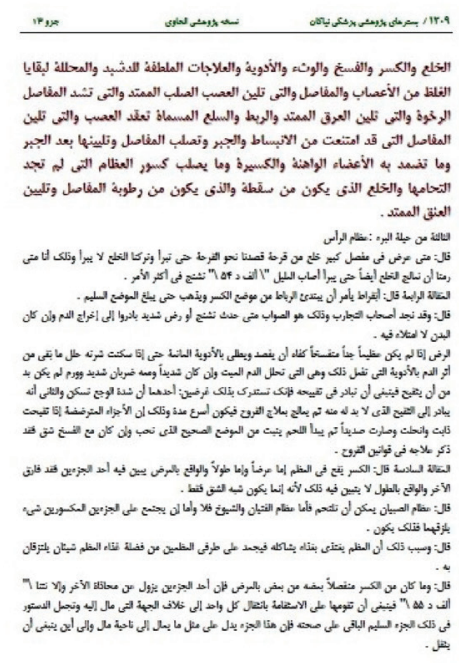

(B)

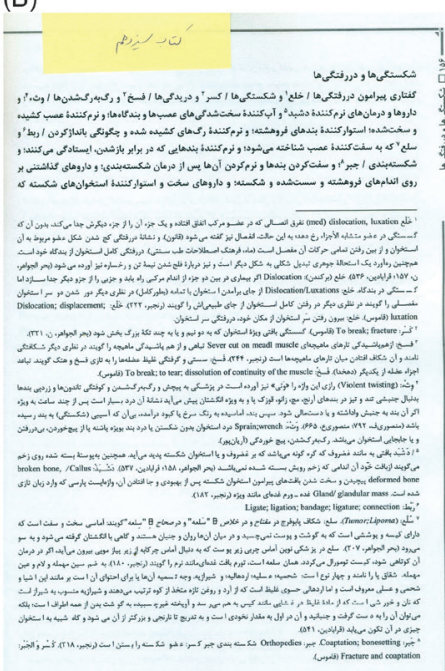


(A)

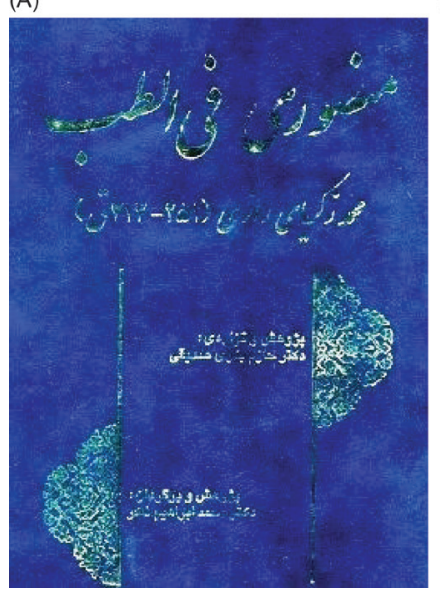

(B)

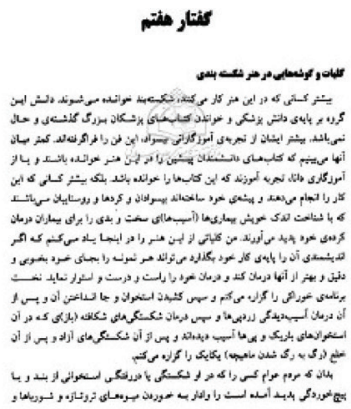

Figure 3. A) Cover of the book "Tebb-e Al Mansouri" in Persian; B) first page of chapter seven on fracture treatment; page 350.

the frame every one or two days and inspecting the fracture site for possible inflammation or infection. Razi's fracture management approach is very similar to the current concept of functional bracing for some fractures. For open fractures and dislocations, priority was given to wound management. Razi advised leaving the fracture wound open to provide drainage of the blood, inflammation, and infection. Razi recommended manipulation and massage with greasy lubricants for softening of the callus of an impending malunion and post immobilization joint stiffness, particularly for fractures near the joints..$^{5-7}$

Razi managed superficial lacerations by dressing and pads to bring the wound edges closer together. Large and deep lacerations were irrigated with vinegar and drugs to induce granulation tissue growth from the wound's depth. He also recommended inserting a wick into the deep wounds with a narrow orifice and keeping the orifice open to prevent pus accumulation. Razi mentioned suturing the wounds and ligation of bleeding large vessels five centuries before Ambroise Pare (1510-1590), the French surgeon, reintroduced the ligation of vessels. He also described cauterization with hot instruments to stop bleeding from arteries. ${ }^{6,7}$

Razi indicated that a matured abscess must be incised, drained, and allowed to heal by itself. Healing of an abscessed wound may be delayed or fail because of insufficient blood in the body, presence of malignancy and necrotic tissues, bone interposition, applying an inappropriate drug, presence of an external body, and varicose veins. ${ }^{6,7}$

Razi described the possibility of infection and decay in recalcitrant chronic ulcers adjacent to the deep bones; therefore, the necrotic bone must be removed by sawing, cutting, and rasping. Removal of the infected and necrotic bone (sequestrectomy) has been established as a principle in the treatment of osteomyelitis. ${ }^{7}$

Razi described that mobile soft tissue masses should be removed with their capsule. In modern tumor surgery, this margin is known as marginal excision. Razi described paronychia and mentioned that the involvement of the nail root may be complicated by loss of the nail plate.

\section{Razi's Concepts on Arthralgia}

According to Dr. Ehsan Moghadas, the book of "Oujay al-Mafasal' (arthralgia in English) is the first independent book written on arthralgia. The book was originally written in Arabic around the year 903. "Oujay al-Mafasal" was translated to Persian under the title of "Al-Hasel fiAlaje Mafasel' by an unknown translator (Figure 4). ${ }^{9}$

Oujay al-Mafasal comprises 22 chapters in which Razi discusses the causes of joint pain, classifies different types of joint pain, mentions the general treatments for joint pain, causes of sciatic pain and its general treatment, causes of hip joint pain, various medications used in therapies, and methods to prevent joint pain. ${ }^{?}$

Razi believed that some organs are strong while others are weak and work under the influence of the strong organs. The strong organs push their products toward the weak organs. Razi hypothesized that the liver, which is a strong organ, digest foods and produces waste materials. The body fails to expel excessive waste produced by the liver; these wastes will alter the balance between the four human humors; the waste materials are forced to accumulate in the joints which are weak organs. According to the Greek school of medicine, the four human humors or temperaments are blood or sanguine, phlegm or plasma, yellow bile which is stored in the gallbladder and black bile which is stored in the spleen. The human temperament alternates between hot/cold and wet/dry temperament predominance. Blood is hot and wet. Phlegm is cold and wet. Yellow bile is hot and dry. Black bile is cold and dry. The altered balance between the four human humors as well as the accumulation of different waste materials in the joints will result in different types of joint pain. ${ }^{9}$

By inspection and palpation of the joints, Razi described hot and cold joint pains. Hot joints are red and warm on 


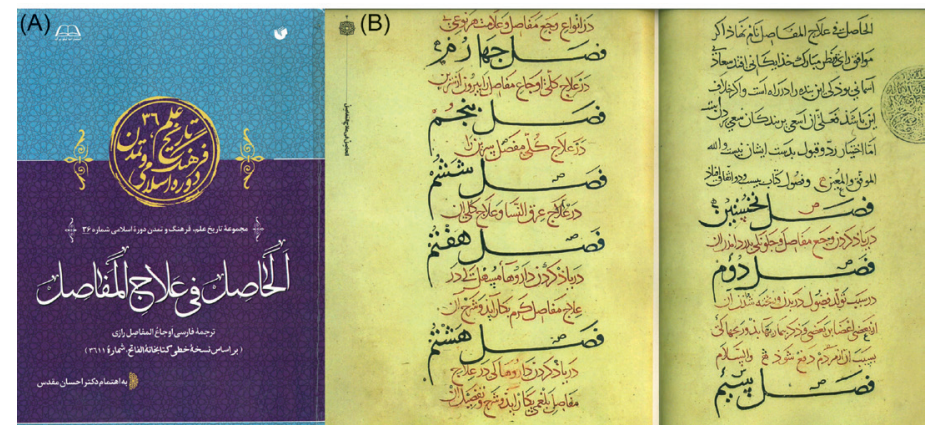

Figure 4. A) Cover of the book "Al- Hasel fi-Alaje Mafasel". (Persian translation of "Oujay al-Mafasal"); B) contents of the book.

palpation. Today's readers may assume that the adjective of hot was used to indicate an inflammatory joint disease. ${ }^{9}$

Razi described the hip joint separately as it is covered by a large mass of muscles and cannot be inspected or palpated. Therefore, the hot or cold nature of the painful hip is obscured; however, Razi noted that the painful hip results in limping and in the long-term, may develop ankylosis. Razi described the sciatic pain as a pain starting in the buttock and radiating through the thigh, leg, and toes. Razi did not attribute the sciatic pain to sciatic nerve involvement; however, he ascribed the sciatic pain because of the changes in the human humors.

Razi's treatments for joint pain including hip and sciatalgia were based on his strong belief in human humors. Therefore, to amend the balance between the human humors, Razi advocated phlebotomy, bloodletting, and inducing vomiting and diarrhea. ${ }^{8}$ Razi made a sharp distinction between arthralgia and gout and prepared an independent treatise on gout in "Maqale fi al-Neqras" (Figure 5). ${ }^{9,10}$

Razi dedicated the treatise to the father of Amir AlMansur Ibn Ishaq, because he suffered from gout. Many modern medical researchers ignore the relation between philosophy and medicine. Razi in "treatise on gout" used a philosophical and Socratic approach, presenting questions and providing answers and descriptions in a simulation of
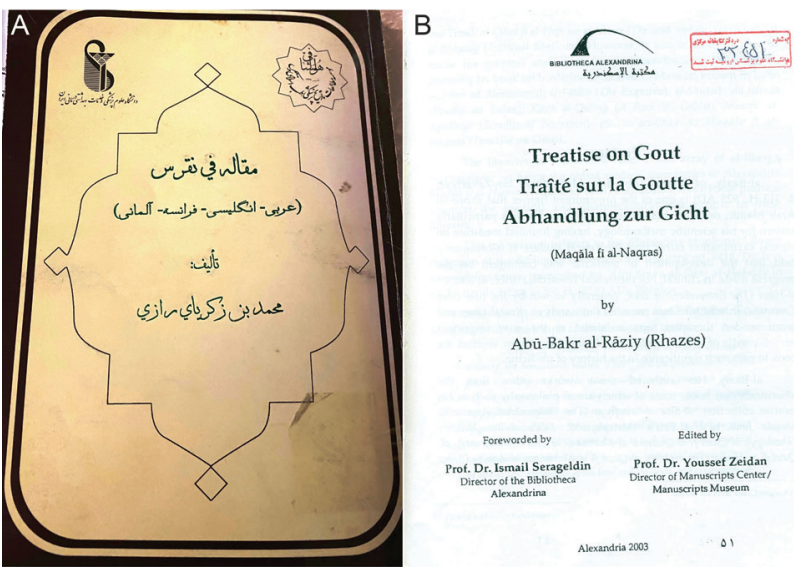

Figure 5. A) Cover of the treatise on gout, "Maqale fi al-Neqras". ${ }^{9}$ B) Front piece and title page in English, German and French. typical Socratic dialogue. The title of each chapter presents a question that every patient may ask and then answer, following a particular purpose. ${ }^{10}$

Razi believed that gout occurs only in the foot joints; while arthralgia in the other joints has causes other than gout. Although Razi was not aware of the purine metabolism and production of uric acid, he correctly indicated that gout is because of the production of a waste substance that the body fails to expel. Upon the accumulation of the waste substance in the foot joints, the symptoms will develop. Razi noticed the effects of sex hormones on gout because he noticed that women before menopause, eunuchs, and males before puberty do not develop gout. ${ }^{10}$

Razi categorized three types of blood: hot biliary, viscoid phlegmatic, and normal. Gout may develop in either of these three blood types. Also, he believed in the influence of foods and liquids in aggravating or alleviating gout. Razi indicated that some normal people with good health but overweight with indulgent eating, consuming alcohol, meat and seafood are more prone to developing gout.' So, gout historically has been known as the "rich man's disease".

To treat and prevent the recurrence of gout, Razi recommended cleaning the body from waste substances. He advocated some diet restrictions to reduce body weight and production of waste substance and expel the waste substance from the body with bloodletting, laxatives, inducing emesis, steam bath and perspiration, and consuming plenty amounts of water and liquids. Also, local application of cold, tepid, or hot water according to different body humors as well as salves and poultices can help to alleviate the foot pain. Razi prepared recipes of drug compounds for different body humors that were based on herbal and botanical medicine to treat and prevent gout recurrence. ${ }^{10}$

In summary, George Sarton, the father of the history of science, has recognized Razi as "the greatest physician of Islam and the Middle Ages." Razi's basic concepts and ideas on bone and joint disorders, treatment of fractures and dislocations, arthralgia, and gout are in line with modern medicine. This brief review describes the antiquity and originality of bone and joint disorders in the medieval 
period in Persia. It can be said that through his written heritage, Razi established the cornerstone for modern orthopedic science.

\section{Authors' Contribution}

Both authors conceptualized, designed and wrote the manuscript.

\section{Conflict of Interest Disclosures}

There is no conflict of interest of any kind in preparing this study.

\section{Ethical Statement}

Not applicable.

\section{References}

1. Modanlou HD. A tribute to Zakariya Razi (865 - 925 AD), an Iranian pioneer scholar. Arch Iran Med. 2008;11(6):673-7.

2. Nayernouri T. Zakariya Razi: the Iranian physician and scholar. Arch Iran Med. 2008;11(2):229-34.

3. Afshar A, Steensma DP, Kyle RA. Razi: Critical Thinker, and Pioneer of Infectious Disease and Ophthalmology. Mayo Clin Proc. 2020;95(5):e53-54. doi: 10.1016/j. mayocp.2020.03.014.

4. Afshar A. Concepts of orthopedic disorders in Avicenna's Canon of Medicine. Arch Iran Med. 2011;14(2):157-9.

5. Zaker ME. Abu Bakr Muhammad ibn Zakariya al-Razi. Al-Hawi fi Tebb, Vol 12. 1st ed. Tehran: Shahid Beheshti University of Medical Sciences, the Center for Traditional Medicine and Medical Research Publication; 2016.

6. Zaker ME. Abu Bakr Muhammad ibn Zakariya al-Razi. Al-Hawi fi Tebb, Vol 13. 1st ed. Tehran: Shahid Beheshti University of Medical Sciences, the Center for Traditional Medicine and Medical Research Publication. 2016.

7. Zaker ME. Abu Bakr Muhammad ibn Zakariya al-Razi. AlMansori fi Tebb. 1st ed. Tehran: Tehran University of Medical Science Publication. 2009.

8. Afshar A. A brief report about the concepts of hand disorders in the Canon of Medicine of Avicenna. J Hand Surg Am. 2011;36(9):1509-14. doi: 10.1016/j.jhsa.2011.06.018.

9. Moghadas E. Abu Bakr Muhammad ibn Zakariya al-Razi. AlHasel fi-Alaje Mafasel. ist ed. Safir Ardahl Publication; 2019.

10. Zeidan Y. Abu Bakr Muhammad ibn Zakariya al-Razi. Maqale fi al-Neqras. Alexander Library Version, Egypt. 